\title{
Desenvolvimento de Ações de Humanização Através um Planejamento Participativo em Hospital Municipal em São Paulo
}

\author{
Ribeiro, Manoel Carlos Sampaio de Almeida; Pint, Antonio Carlos Guimarães S.;
} Cuginotti, Aloisio A.; Murakami, Valdemar; Irano, Rosangela; Lima, Sabrina

FCMSCSP — mcrmacal@gmail.com

Introdução: a PNH é definida como uma política transversal, que perpassa as diferentes ações e instâncias gestoras do SUS, orientada pela valorização da autonomia dos usuários, trabalhadores e gestores, pela construção de vínculos solidários e pelo compromisso com a ambiência, melhoria das condições de trabalho e assistência. Assim a humanização é tida como uma referência para realização de mudanças para melhoria da qualidade da assistência e para enfrentamento dos desafios da gestão hospitalar. Objetivo: incrementar as ações de humanização no hospital através de oficinas de planejamento participativo. Metodologia: como estratégia de intervenção foi desenvolvida uma capacitação composta por discussões teóricopráticas, leituras e oficina de planejamento com profissionais de saúde do hospital. em função das limitações de tempo, optou-se por trabalhar com 3 áreas do hospital: maternidade, emergência e UTI. Além disso, estrategicamente, escolheu-se como tema norteador da oficina de planejamento a inserção da rede social e afetiva dos usuários nos espaços assistenciais, entendendo que a implementação desta diretriz da $\mathrm{PNH}$ exige uma série de pré-condições relacionadas as demais diretrizes. a oficina de planejamento foi realizada com grupos de trabalho representativos de cada área (45 pessoas), utilizando uma "Matriz SWOT" e Planejamento Participativo. Resultados: no hospital já existe implantado um GTH no entanto as ações ainda são incipientes, em fase de transição da gestão. As grandes diretrizes da Política Nacional de Humanização como, por exemplo, a Visita Aberta, a prática da Clínica Ampliada e até mesmo a Classificação de Risco ainda não estão totalmente disseminadas no hospital, que carece de um planejamento mais amplo e envolvente. na área de Obstetrícia as ações de humanização estão melhor desenvolvidas, contemplando a presença do familiar no momento do parto As questões referentes à Humanização na UTI e na área da Emergência são muito pontuais e pouco representativas das necessidades da população assistida. Principais resultados: na UTI: Ter a equipe multiprofissional completa (EQUIPE TÉCNICA); Reforma da UTI (AMBIÊNCIA); Melhorar a comunicação com familiares (RELAÇÃO INTERPESSOAL) na MATERNIDADE: Aumentar a privacidade das parturientes cortinas nos:boxes (AMBIÊNCIA); Elaboração de uma Cartilha do Usuário (RELAÇÃO INTERPESSOAL); Implantar a manutenção preventiva regular (EQUIPAMENTOS) na EMERGÊNCIA: Implantar o Grupo de Trabalho de Humanização (GESTÃO); Reformar o PS para adequar à demanda e melhorar as condições assistenciais ao doente (AMBIÊNCIA); Realizar Seminário "Acolhimento com Classificação de Risco" e Melhorar a comunicação equipe técnica e os familiares (COMUNICAÇÃO) Conclusão: Houve uma importante mobilização no hospital; um plano aplicativo de ações com cronograma foi desenvolvido deverá ser implementado e avaliado em 4 meses; o GTH está sendo reativado

Ribeiro, Manoel Carlos Sampaio de Almeida; Pint, Antonio Carlos Guimarães S.; Cuginotti, Aloisio A.; Murakami, Valdemar; Irano, Rosangela; Lima, Sabrina. Desenvolvimento de Ações de Humanização Através um Planejamento Participativo em Hospital Municipal em São Paulo. In: Anais do Congresso Internacional de Humanidades \& Humanização em Saúde [= Blucher Medical Proceedings, num.2, vol.1]. São Paulo: Editora Blucher, 2014. ISSN 2357-7282

DOI 10.5151/medpro-cihhs-10607 